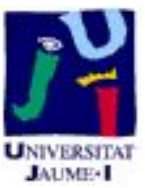

Título artículo / Títol article:

Methodology to design a municipal solid waste generation and composition map : A case study

Autores / Autors:

Gallardo Izquierdo, Antonio ; Carlos Alberola, María del Mar ; Peris Mendoza, Mónica ; Colomer Mendoza, Francisco José

Revista:

Waste Management, 2014, 34.11

Versión / Versió:

Post-print

Cita bibliográfica / Cita bibliogràfica (ISO 690):
GALLARDO, A., et al. Methodology to design a municipal solid waste generation and composition map: A case study. Waste Management, 2014, 34.11: 1920-1931.

url Repositori UJI: 


\title{
METHODOLOGY TO DESIGN A MUNICIPAL SOLID WASTE GENERATION AND COMPOSITION MAP: A CASE STUDY
}

\author{
Gallardo, A.; Carlos, M.; Peris, M; Colomer, F.J.
}

Antonio Gallardo: Ph D. Professor. Dept. Mechanical Engineering and Construction. Jaume I University, Av. de Vicent Sos Baynat s/n. 12071 Castelló de la Plana, Spain. Email gallardo@uji.es

Mar Carlos (Corresponding Author): Ph D. Professor. Dept. Mechanical Engineering and Construction. Jaume I University, Av. de Vicent Sos Baynat s/n. 12071 Castelló de la Plana, Spain. E-mail mcarlos@uji.es. Tel. +34 964728114.

Mónica Peris: Ph D. Researcher. Dept. Mechanical Engineering and Construction. Jaume I University, Av. de Vicent Sos Baynat s/n. 12071 Castelló de la Plana, Spain. Email perism@uji.es

Francisco J. Colomer: Ph D. Professor. Dept. Mechanical Engineering and Construction. Jaume I University, Av. de Vicent Sos Baynat s/n. 12071 Castelló de la Plana, Spain. E-mail fcolomer@uji.es

\begin{abstract}
The Municipal Solid Waste (MSW) management is an important task that local governments as well as private companies must take into account to protect human health, the environment and to preserve natural resources. To design an adequate MSW management plan the first step consist in defining the waste generation and composition patterns of the town. As these patterns depend on several socio-economic factors it is advisable to organize them previously. Moreover, the waste generation and composition patterns may vary around the town and over the time. Generally, the data are not homogeneous around the city as the number of inhabitants is not constant nor it is the economic activity. Therefore, if all the information is showed in thematic maps, the final waste management decisions can be made more efficiently. The main aim of this paper is to present a structured methodology that allows local authorities or private companies who deal with MSW to design its own MSW management plan depending on the available data. According to these data, this paper proposes two ways of action: a direct way when detailed data are available and an indirect way when there is a lack of data and it is necessary to take into account bibliographic data. In any case, the amount of information needed is considerable. This paper combines the planning methodology with the Geographic Information Systems to present the final results in thematic maps that make easier to interpret them. The proposed methodology is a previous useful tool to organize the MSW collection routes including the selective collection. To verify the methodology it has been successfully applied to a Spanish town.
\end{abstract}

Key words: MSW; generation; composition; Map; GIS; methodology 


\section{Introduction}

Municipal solid waste (MSW) management is an environmental problem of major relevance for all societies. In fact, both citizens' and politicians' concern about waste management has been growing in recent decades due to the fast increase in waste generation (Castagna et al., 2013; Sakai et al., 2011). This is a consequence of the quick growth of the population, especially the urban population, and the rise in waste generation rate, as a result of a progressively quicker obsolescence of products and the new packing systems used for these products. In Western Europe, per capita MSW generation increased from $474 \mathrm{~kg} \mathrm{y}^{-1}$ in 1995 to $500 \mathrm{~kg} \mathrm{y}^{-1}$ in 2011 , which means a rise of 6\% (Eurostat, 2013). Nevertheless, there are great differences in MSW from one European city to another; for instance, MSW generation rates in European Union-15 cities were far higher $\left(510 \mathrm{~kg} \mathrm{inh}^{-1} \mathrm{y}^{-1}\right)$ than the Central and Eastern European cities $\left(354 \mathrm{~kg} \mathrm{inh}^{-1} \mathrm{y}^{-1}\right)$ in the year 2000 (Beigl et al., 2004).

There are several factors, such as physical, geographical, socio-cultural, economic and political ones, which have an influence on the composition and generation of MSW. To manage MSW adequately it is essential to know these variables as precisely as possible in a specific geographic area. Hence, the factors that affect MSW composition and generation must be studied, as well as their variation over time.

One of these factors to be taken into account is the "season" factor. This is related to MSW generation and composition due to the different patterns of consumption people have depending on the seasons or the climate. For instance, Gómez et al. (2009) pointed out that the smallest amount of MSW appears when temperatures are lower. This fact may be a consequence of the consumption of a greater amount of organic matter and drink containers during seasons with higher temperatures. Other types of waste, such as garden waste, might be crucial in neighbourhoods with private gardens. In this way, Boldrin and Christensen (2010) found large differences in the amounts of garden waste produced throughout the year in the city of Aarhus (Denmark).

Another factor to be taken into account is the difference in "economic level" between high- and low-income areas. These differences are reflected in the composition and generation of MSW. In fact, high-income areas usually produce more inorganic materials such as plastics and paper, while low-income areas produce relatively more organic waste (Gallardo, 2000; Emery et al., 2003). Several authors found relations between income and waste generation with great (Gómez et al., 2009) or weak differences (Dahlén et al., 2009). Moreover, Keser et al. (2012) established a statistically significant influence between unemployment rate, as an indicator of the economic level, and the decrease in MSW generation in Turkey. Indeed, according to Bandara et al. (2007), a representative neighbourhood of each income level might be used to predict MSW generation in a city. MSW production, however, is not as directly proportional to gross domestic product (GDP) as is often expected (Sokka et al., 2007). In fact, Mazzanti et al. (2008) noted that several studies conducted in industrialised countries, where policies and waste management are highly developed, had obtained different results when analysing waste generation and its relation with income. In these cases, the policies applied exert a strong influence on MSW generation.

Population movement during holiday periods is another factor that affects generation and composition of MSW in a specific area. In fact, coastal areas have to adapt their waste management, as there is a growth in the number of inhabitants in certain periods of the year (Ariza et al., 2008). Furthermore, there is a certain degree of heterogeneity between the amount and composition of waste generated by tourists and residents (Mateu-Sbertet et al., 2013). 
"Type of Town" must also be taken into account as there are differences in waste generation depending on the main activity of the zone. According to Pitchel (2005) and Zaman and Lehmann (2011), this activity can be classified as residential, commercial, institutional or industrial. Cherian and Jacob (2012) classified the MSW in urban areas as residential areas (households), commercial areas (markets, supermarkets, department stores, hotels, etc.), industrial areas and institutional areas (cinema, theatres, educational centres, museums, private and governmental offices, etc.).

How these variables influence MSW generation and composition in a specific area and their relations can be expressed by means of a mathematical model. In fact, there are many works that model MSW generation. For example, Daskalopoulos et al. (1998) analysed how population and the mean standard of living of the country affect MSW generation. Beigl et al. (2004) obtained equations that established a relation between the amount of MSW and the national indicators of development (such as GDP per capita, infant mortality rate, life expectancy at birth, etc.). Moreover, Ibáñez et al. (2011) modelled the degree of waste separation taking into account demographic and socioeconomic factors, since these characteristics affect citizens' behaviour when it comes to separating waste fractions (paper/cardboard, glass and packaging). As there is a great number and variety of MSW models, Beigl et al. (2008) reviewed previous works in order to categorise them, and Cherian and Jacob (2012) focused their review on models that have considered socio-economic factors.

To analyse all these factors together and their influence on MSW generation in a specific area, it is necessary to use robust tools, such as the Geographic Information System (GIS) environment. The use of GIS in MSW management (Rada et al., 2013) offers a number of advantages. Karadimas and Loumos (2008) considered that GIS would allow the process of waste planning and management to be automated. Chalkias and Lasaridi (2011) identified two main categories of GIS-based waste management applications in the international literature: the first one refers to the GIS used to select the location of the waste facilities, and the second one is concerned with GIS-supported waste management applications related to waste collection. The second group includes several proposals in developing countries (Keser et al., 2012) as well as in high-income countries (Ericsson et al., 2006; Anghinolfi et al., 2013; Santos et al., 2008; Zamorano et al., 2009; Gallardo and Bernad, 2011; Rada et al., 2010). GIS is also used to perform MSW management as it provides a powerful context in which to import, to manage and to analyse spatial data (Anghinolfi et al., 2013; Chalkias and Lasaridi 2011). In this sense, it is a suitable tool for producing a MSW map.

Knowing MSW generation and composition, its temporal variation and its spatial distribution is essential to design a waste management plan (Gómez et al., 2009; Bandara et al., 2007). These data can also have an influence on the design of treatment plants and landfills and when it comes to determining the number of containers that are necessary in a town or city (Ragazzi and Rada, 2008; Ionescu et al., 2013; Economopoulos et al., 2012).

The purpose of this paper is to establish a methodology to design a MSW map using GIS, which will make it possible to obtain a spatial distribution of MSW within a specific geographic area taking into account its generation, composition and variation throughout the year. The final part of this methodology allows the creation of an accurate map showing the MSW spatial distribution, because it considers the specificities of the study area. The waste map will enable waste managers to plan a good MSW management. Once the map has been drawn, it will make several activities involved in waste management easier, including the placement of the containers, selective collection organization or the design of the MSW collection routes. In this 
work the proposed methodology has been applied to a Spanish city to show it is a valid tool.

\section{Methodology}

MSW management involves several steps that need to be analysed: waste generation, waste pre-collection, waste collection, waste treatment and waste final disposal. The amount and composition of the waste generated represents the basic information for designing a waste management system. Furthermore, in the waste collection step, it is necessary to know the temporal variation and the spatial distribution of MSW in the location where plans have been made to apply a waste management system. Therefore, it is advisable to draw up a map with generation and composition data.

It is necessary to develop a methodology that can explain how to obtain suitable and accurate information and how to map it. The proposed methodology is structured in four steps. Additionally, the methodology contemplates two different ways of designing a MSW map: a direct way or an indirect way. In the first case, as the main goal is to obtain an exact map of MSW generation and composition, it is necessary to acquire a huge volume of data about the study area. The user will need spatial data about MSW generation, composition and their variation over the time in every generation point of the study area. Since this calls for a great amount of information, it will surely involve an important economic effort (e.g. field work, sampling, etc). However, in the second case, if the user does not have enough detailed information about the study area, it is suggested to use data from similar areas and some theoretical coefficients. In the second way, the economical effort is lower as less information is demanded. Figure 1 describes each step of the methodology: the problem definition, the information search, the street network design, and finally the design of the MSW map.

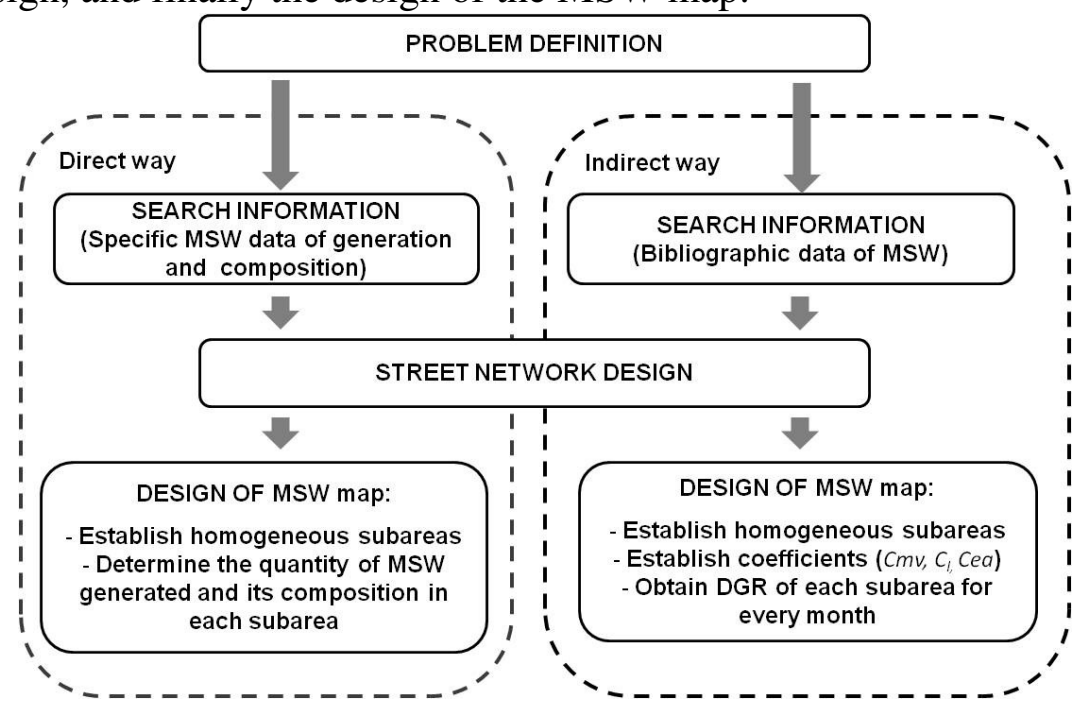

Figure 1.Stages of the proposed methodology.

\subsection{Problem definition}

The first step of the methodology is to define the problem, as well as to state the aims and restrictions. First, the study area must be located and its geographical limits must be established and, second, it is necessary to identify the MSW fraction that is to be managed, such as commercial waste, household waste or specific waste (e.g. hazardous 
waste). In order to define the data needed in each case, the collection system must be previously selected.

The final user of the methodology must consider and set the main purpose of the MSW map, as well as the resources available to produce it, in order to select the most suitable way in each case. Regardless of the selected way, the map scale must be defined, as it will condition the amount of data that must be generated and processed.

\subsection{Information search}

It is important to obtain information about the factors pointed out in the introduction, which have an influence on MSW generation and composition, in order to assess their specific impact on MSW in the study area. Therefore, the following information must be searched:

- Spatial distribution of population: This information is necessary to know exactly where the MSW is generated, including isolated points which might be collected separately.

- Population density: Several authors have estimated MSW generation taking into account the population density (e.g. Vijay et al., 2005; Bandara et al., 2007), since this factor conditions MSW generation. Furthermore, there are usually differences amongst the neighbourhoods of a town due to the type of housing (e.g. apartments, detached or semi-detached houses, etc.). For this reason, it is useful to achieve detailed information about population density in each neighbourhood.

- Seasonal variation of population: The population of some urban areas can vary considerably during the year. For example, there are places where inhabitants move to touristic areas in summer. In these cases, the number of inhabitants decreases in that period. In contrast, other areas receive large numbers of residents. Therefore, if there are differences in seasonal population behaviour in the study area, it is essential to establish where the population increases and decreases or if there are no changes in this respect. In fact, the huge growth in population forces the town council to reorganise MSW collection. Mendes et al. (2013) found that in Loule (Portugal) the quantities and composition of MSW generation show a clear intra-annual variability. These differences are due to the increase in population and in some cases to the different behaviour of tourists and native citizens regarding waste generation (Mateu-Sbert et al., 2013).

- Economic activity: The city under study must be divided into areas according to the main economic activity in each case, such as the residential zone, commercialresidential zone, industrial zone or commercial zone. The residential zone is defined as the sectors mainly occupied by private residences where people live. The industrial zones are those areas planned to carry out industrial activity. Commercial zones are the areas that contain shops and services but where there are no houses. Commercialresidential zones consist of areas where shops, restaurants and other services basically occupy the ground floors of the buildings and there are flats on the other floors. Generally, there is no detailed information about the spatial distribution of these areas and the methodology user must establish these limits within the study area.

- Type of commercial areas: Commercial areas can be divided into two types depending on the main type of waste generated. There are areas where the main type of waste is wet solid waste, for example in markets, groceries, etc., and other areas where the waste is mainly dry waste, such as packaging for example in department stores, clothes shops, etc. To classify each commercial area depending on the kind of waste generated is important in order to decide whether a certain type of commercial waste needs to be 
collected separately. For this reason, a spatial distribution of the different types of shops in the study area is necessary.

- Economic level of population: A town can be divided into subareas from the citizens' income point of view. As there is no single system to establish the number of income levels in order to classify the population, the methodology user must decide on the number of levels taking into account the regulations in the study area. To analyse MSW generation, several authors (DPC, 1992; Szantó et al., 1992; García, 1998; Bandara et al., 2007) use four income levels: high income, medium-high income, medium income and low income. Other authors, e.g. Gómez et al. (2009), compare waste generation in households at three socio-economic levels (lowest level: 1-2 times the minimum wage; medium level: 2-5 minimum wage; highest level: more than 5 minimum wage). The spatial data of the economic level of the population should be mapped in order to provide the spatial economic variation in the study area.

- Season: Seasons affect MSW generation due to their influence on several behaviours. For instance: in winter, there is more ash in cold areas than in hot areas, whereas in summer there is more organic waste in hot areas than in cold areas. In fact, Troschinetz and Mihelcic (2009) pointed out that the amount of organic waste generated changes depending on seasons or climate. The information about these factors could be provided by public authorities, official statistics or socio-demographic studies in the study area. Additionally, if there is a lack of information, some extra fieldwork will have to be carried out.

It is also essential to know the monthly (or weekly) MSW generation and composition in each subarea, each neighbourhood, each street, or even in each street segment. If these data are not available, they should be obtained by sampling. When detailed MSW data are not available and obtaining them requires a great effort, it is necessary to know at least the mean values in the study area.

\subsection{Street network design}

A digital representation of the street network, more specifically as vector data, is essential to generate a MSW map. A well-designed street network, with a population database, will allow detailed information about MSW generation and composition to be shown. It will be essential for proper MSW management, particularly to make an adequate assessment of MSW collection and of the number of bins needed. In order to produce the street network, some previous steps must be considered:

- To obtain a digital cartography: Nowadays, a great number of digital cartography sources are available to obtain street data (e.g. Census TIGER streets, ESRI streets, commercial streets like Tele Atlas or NAVTEQ or custom streets like the ones created by local agencies). The most suitable digital cartography of the study area must be selected to draw up a MSW map. Analogue information should be digitalised to obtain a vector data set when there is no digital cartography available.

- A Cartography treatment: The street data must usually be updated to achieve satisfactory results, although this work could take a long time. It is especially important in towns with a fast urban growth, where new streets and buildings are continuously being created. Moreover, the cartography must be debugged in order to correct possible errors, such as undefined lines, unnecessary or repeated information and closed plotlines like polygons, which can difficult further analysis of the information.

- Streets outline: In this step all the streets must be drawn to build the road network: lines represent streets and junctions represent crossroads. All lines must be perfectly 
connected and each line has a database allocated to it that characterises the street and MSW generation data.

- Linear density of population: In this step, the population data must be assigned to the street network, specifically information about linear population density. This is useful to estimate the amount of MSW generated per unit of pavement length $(\mathrm{m})$. Three methods are suitable to obtain the linear population density depending on the information available and its accuracy:

a) A digital map that includes a database with the number of households and the number of inhabitants per household. These data will provide the exact number of inhabitants per linear metre of street.

b) The Registry of inhabitants, which provides spatial data about the population in the town, which is in turn divided into areas (e.g. districts and sections). The length of the streets in each area should be measured to obtain the linear density of every area. Therefore, the final information is not as detailed as the information obtained with the previous method.

c) Another option to estimate the linear density when there is no detailed information about population distribution would be to divide the study area into homogeneous areas depending on the building height, the number of flats per floor and the number of inhabitants per flat.

- Shop distribution: To draw up a MSW map it is essential to add a field in the database with information about the number of shops (e.g. markets, shopping centre, supermarkets, etc.) per street and their sizes. It is also essential to specify the type of commercial business.

\subsection{Designing the MSW map}

At this point, the MSW information must be assigned to the street network of the study area. When there are differences in waste generation and composition, the study area should be previously divided into homogeneous subareas. A homogeneous subarea is a spatial area with a similar MSW composition and the same daily generation rate (DGR) of MSW per inhabitant. In order to obtain these subareas, firstly, the factors that affect MSW generation and composition must be analysed and the results should be reflected as thematic maps. Table 1 shows the factors used and the categories which these factors are divided into. Once each map has been drawn, they must be intersected as shown in Figure 2.

Table 1. Factors that affect MSW generation.

\begin{tabular}{ll}
\hline Factor & Example of Categories per each factor \\
\hline Spatial distribution of population: & $\begin{array}{l}\text { Number of urban centres in the study area } \\
\text { Only indicates if there is any increase, decrease or non- } \\
\text { veasonal variation of population: }\end{array}$ \\
$\begin{array}{l}\text { Industrial, commercial, residential (apartments), residential } \\
\text { (semi-detached and terraced houses), commercial-residential }\end{array}$ \\
Economic activity: & $\begin{array}{l}\text { Use four income levels, such as high income, medium-high } \\
\text { income, medium income and low income }\end{array}$ \\
Economic level of population: & If commercial waste is collected separately, as some collection \\
Type of commercial areas: & systems reflect, it should be interesting to know the types of \\
& waste generated in each sector \\
Linear density of population: & Three levels can be used: high, medium and low linear density \\
Season: & MSW data of each season or month \\
\hline
\end{tabular}




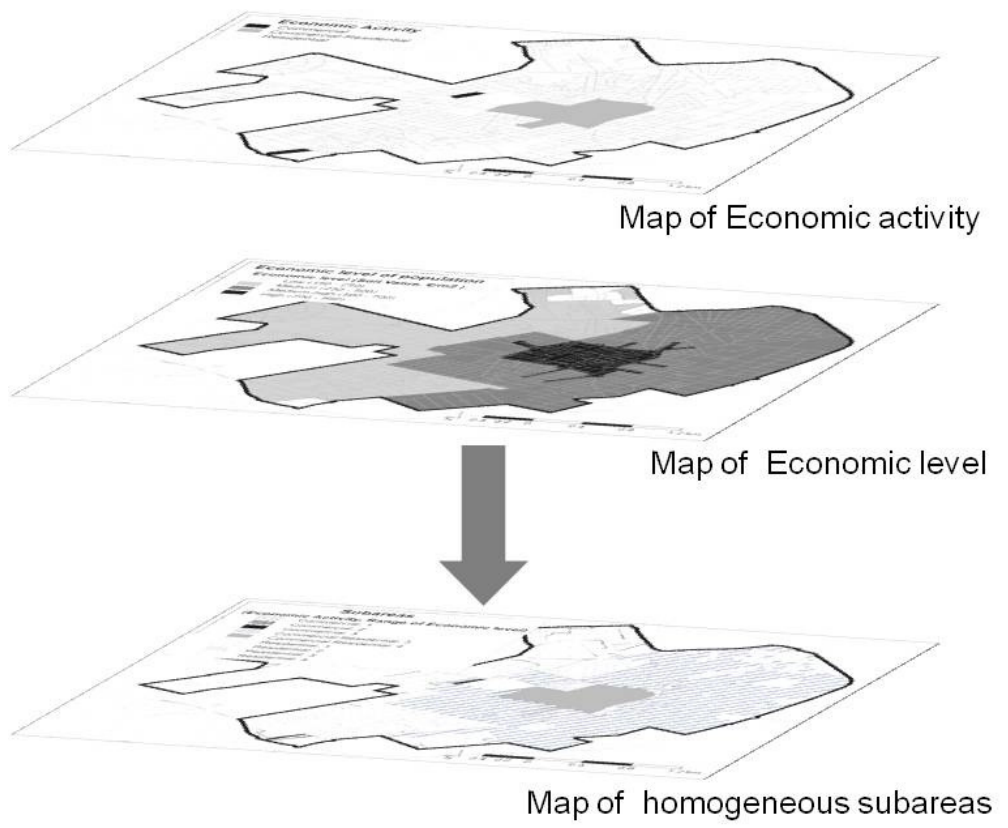

Figure 2. Map of homogeneous subareas as a result of intersection of thematic maps.

\subsubsection{The direct way}

As mentioned above, depending on the information available, there are two ways to achieve a MSW map. In the first option, the MSW generation and composition data must be assigned to each subarea. The exact information to be entered is the MSW generation per metre of street and its composition. Nevertheless, if there is not enough information to complete the map, a suitable plan should be designed to obtain that information. The sampling plan should consider the monthly variability of the MSW generation and the seasonal variation of its composition. Afterwards, this information must be included in the map.

In order to know the amount of waste generated, the MSW samples of each waste fraction should be collected in several homogeneous neighbourhoods, both in households as well as in shops. In this process, the neighbourhood variability per month must be considered. To know the MSW composition, these samples should be characterised. It is important to remark that the sampling process must be carried out in different seasons.

If all the required data are available, the methodology is faster and more accurate than if it must be searched for. Nevertheless, it will be a long expensive job when all the field work has to be carried out to achieve detailed information. For this reason, the indirect way is presented below.

\subsubsection{The indirect way}

In this option, first of all, it is essential to know at least the average values of MSW generation and composition in the study area as well as their monthly values. However, if there is a complete lack of information about this in the study area, the data for MSW generation and composition can be obtained from bibliographic information for similar areas. Second, coefficients that balance MSW generation and composition are established taking into account the spatial and temporal distribution of these variables in the study area or in previous research conducted in the study area or in similar places. 
Finally, waste generation and composition in each subarea must be calculated as follows.

In order to calculate Daily Generation Rate per month in each subarea $\left(D G R m_{i, l}\right)$, some additional information is needed, such as:

- Annual Generation Rate per inhabitant (AGR), which shows the annual generation of MSW per person in the study area.

- Monthly variation coefficients $\left(\mathrm{Cmv}{ }_{i}\right)$, which indicate the generation variation related to the average monthly generation.

- Income coefficients $\left(C_{I} l\right)$, which show how income levels have an influence on average waste generation in the study area.

- Economic activity coefficients $\left(\mathrm{Ce} a_{l}\right)$, which indicate how economic activity influences MSW generation rate in the town under study.

The DGRm $\mathrm{i}_{\mathrm{i}, 1}$ of each month in each type of subarea can be calculated using the following equation (1):

$D G R m_{i, l}=\left(A G R \cdot C_{I l} \cdot \mathrm{Cea} l_{l} \cdot \mathrm{Cm} v_{i}\right) /\left(12 * x_{i}\right)$

where $D G R m_{i, l}$ is the daily generation rate of month $i$ in subarea $l\left(\mathrm{~kg} \mathrm{inh}^{-1} \mathrm{y}^{-1}\right) ; A G R$ is the annual generation rate $\left(\mathrm{kg} \mathrm{inh}^{-1} \mathrm{y}^{-1}\right) ; C m v_{i}$ is a monthly coefficient of month $i ; C_{I l}$ is the Income coefficient in subarea $l ; \mathrm{Ce}_{l}$ is the economic coefficient in subarea $l ; \mathrm{x}_{\mathrm{i}}$ is the number of days in month $i$.

To calculate the MSW composition of each subarea, the following information is needed:

- Annual average composition in percentage of weight of each MSW fraction in the study area (Pave ${ }_{k}$ ).

- Variation Coefficient of each fraction taking income $\left(C c_{I} k\right)$ into account. This coefficient reflects how the percentage of each recovery fraction $(k)$, such as glass, paper-cardboard, lightweight-packaging, etc., is affected by the different levels of the population income in the study area.

- Variation Coefficient of each fraction taking economic activity $\left(C_{c e} a_{k j}\right)$ into account. This coefficient reflects how the percentage of each fraction $(k)$ is affected by the economic activity carried out in each subarea $(j)$.

- Coefficient of monthly variation of each fraction $\left(C m v c_{k i}\right)$. This coefficient refers to the percentage variation of the fraction $k$ in month $i$ related to their annual percentage.

The percentage of each fraction $\left(P_{k}\right)$ of each month $(i)$ of each subarea $(k)$ would be obtained with equation (2):

$P_{k i j}=$ Pave $_{k} \cdot C c_{I k} \cdot$ Ccea $_{k j} \cdot C m v c_{k i}$

where $i$ is the month; $k$ is the fraction type (glass, paper-cardboard, mixed waste, lightweight-packaging, etc.); $l$ indicates the subarea (commercial, residential, etc.); $P_{i j k}$ is the percentage by weight of fraction $j$ in the subarea $j$ for month $i$; Pave ${ }_{k}$ is the annual average percentage by weight of fraction $k$ in the city; $C c_{I k}$ is the variation coefficient of fraction $k$ related to income; Ccea ${ }_{k j}$ is the variation coefficient of fraction $k$ related to the economic activity of subarea $j$; and $C m v c_{k i}$ is the variation coefficient of fraction $k$ in month $i$.

In order to calculate the spatial variability of the annual generation rate per metre $\left(\mathrm{kg} \mathrm{m}^{-}\right.$ ${ }^{1}$ ), spatial information about population linear density $(P l d)$ in each subarea is needed. This information could be obtained as explained in point 2.3 and it must be joined to the AGR in each subarea to obtain homogeneous areas taking into account both variables. In this step the product of AGR and Pld of each subarea will provide information about spatial MSW generation (MSW kg m${ }^{-1}$ pavement). If the MSW composition is known, it is also possible to obtain the amount of each fraction generated. 


\section{Case study}

To validate the proposed methodology, it was applied to the town of Castellón (Spain). The results are shown step by step in maps and tables to facilitate their understanding. The final goal is to represent a MSW map where the town appears divided into zones according to their MSW generation and composition.

\subsection{Problem definition}

As mentioned above, the town analysed in this study is Castellón, which is located on the east coast of Spain. In this town there are two settlements, the main settlement is the urban centre and the other is the maritime district, which is $5 \mathrm{~km}$ from the first one. In this town, waste is separated into four fractions: paper/cardboard, glass, lightweight packaging and mixed waste. The mixed waste is picked up from kerbside bins in containers of 1,100 1, whereas the paper/cardboard, glass and packaging are collected in 3,200 1 containers from drop-off points that have a radius of action of $100 \mathrm{~m}$ (Gallardo et al., 2011; Gallardo et al., 2012).

The main objective of the MSW map will be to design a selective MSW collection system that will cover the entire urban centre. The study area comprises the urban centre except the commercial areas and the industrial parks because commercial and industrial wastes are managed by private companies. In this case, the indirect way was selected to obtain the MSW map taking into account the available data about the area and the bibliographic information. In this case, there was not enough budget in order to produce generation and composition data in each subarea.

\subsection{Information search}

In this section, the information about each factor in the study area is shown following the proposed methodology. These data have been obtained from several sources such as the Spanish Statistics Institute (INE, 2012), Valencia Statistics Institute (IVE, 2012), the Instituto Geográfico Nacional (IGN) (2012), Register of Inhabitants (2010) and the Castellón Town Council. The information that must be searched for is detailed below:

- Spatial distribution of population: Castellón has a population of 180,204 inhabitants. The town covers an area of $108.8 \mathrm{~km}^{2}$ and has an average population density of 1,655.7 inh $\mathrm{km}^{-2}$ (IVE, 2012). The study area had a population of 163,801 inhabitants and its spatial distribution is heterogeneous (Castellón Town Council, 2010). Following the register of inhabitants, the town is divided into 9 districts and 100 sections, each section containing between 1,000 and 2,000 inhabitants. In some of them there are blocks of flats, whereas in others there are semi-detached or detached houses. Furthermore, there are also several areas without any buildings in the urban centre.

- Seasonal variation of population: In this town, the population decreases during the summer, especially in August, because inhabitants move to other coastal towns and villages. There are no differences in the study area amongst districts, as the entire area shows a decrease in the summer season.

- Economic activity: The town council provided information about the main use of each plot of land. These data refer to eleven economic activities (education, commercial, hotels, households, industries, offices, public administration, religious buildings, entertainment, sports facilities and warehouses). The land without any type of buildings has been also considered. Since there were too many types of activities, they have been grouped to reduce their number. 
- Type of commercial areas: As the town council does not have a complete classification of the commercial areas, this information has not been analysed in this case study. Moreover, the commercial waste is not taken into account because it is managed by private companies.

- Economic level of the population: As the spatial distribution of the income in Castellón is not available, according to Gallardo et al. (2011), a suitable indicator of the economic characteristics could be the type of building. These authors found differences in the rates of separation of cardboard/paper and lightweight packaging fractions between low and high income neighbourhoods in Castellón when housing values are taken as an income indicator. In this sense, according to Emery et al. (2003), different socio-economic statuses in the form of different types of dwellings have an influence on the final quantities and composition of waste disposal, which are in some cases quite substantial.

According to the data provided by the Town Council, Castellón is divided into 178 land value zones that have been evaluated taking into account their location, accessibility, housing development, urban services quality, and the real estate market dynamics. As a result, each area of the town has its own land economic value $\left(€ \mathrm{~m}^{-2}\right)$. Therefore, these zone values are a good indicator of the economic characteristics to divide the town into homogeneous subareas.

- Climate: The climate in the study area is a typical Mediterranean climate, which means cool wet winters and hot dry summers. Castellón has an average temperature of $17.8^{\circ} \mathrm{C}$, an annual thermal amplitude of $13.5^{\circ} \mathrm{C}$ (Vicente et al., 2011) and an annual average rainfall higher than $442 \mathrm{~mm}$. There are no climatic differences amongst the districts of the town as the study area is not big enough.

- MSW data of generation and composition: The total generation of MSW in Castellón in 2012 was 67,307.42 t (Table 2). The MSW generation rate in Castellón was 373.51 $\mathrm{kg} \mathrm{inh}^{-1} \mathrm{y}^{-1}$ and $1.02 \mathrm{~kg} \mathrm{inh}^{-1} \mathrm{~d}^{-1}$ in 2012. The MSW comprises all waste generated in the city except the waste generated in the beach zone, the green points, and bulky waste. MSW generation decreases in summer, as a result of the inhabitants' moving to tourist areas, as mentioned before. In fact, table 2 shows that paper-cardboard and lightweight packaging generation are smallest in August. The average composition, in weight, of the MSW in the town of Castellón is as follows: 57\% organic material, $15 \%$ paper/cardboard, $10 \%$ lightweight packaging, $7 \%$ glass, $4 \%$ metal, $4 \%$ textile and 3\% others (Bovea et al., 2010).

Table 2. Monthly generation of MSW and selective fractions in 2012.

\begin{tabular}{|c|c|c|c|c|c|}
\hline & $\begin{array}{c}\text { Paper/ } \\
\text { cardboard } \\
\text { (tonnes) }\end{array}$ & $\begin{array}{c}\text { Lightweight } \\
\text { packaging } \\
\text { (tonnes) }\end{array}$ & $\begin{array}{c}\text { Glass } \\
\text { (tonnes) }\end{array}$ & $\begin{array}{c}\text { Mixed } \\
\text { waste } \\
\text { (tonnes) } \\
\end{array}$ & $\begin{array}{c}\text { MSW } \\
\text { (tonnes) }\end{array}$ \\
\hline January & 248.08 & 98.52 & 132.90 & $5,024.08$ & $5,805.20$ \\
\hline February & 210.07 & 91.24 & 86.82 & $4,526.28$ & $5,196.43$ \\
\hline March & 232.68 & 96.00 & 133.51 & $5,242.16$ & $6,094.73$ \\
\hline April & 224.66 & 98.30 & 86.87 & $4,846.66$ & $5,551.59$ \\
\hline May & 212.61 & 99.14 & 106.04 & $5,188.44$ & $5,957.37$ \\
\hline June & 221.31 & 94.96 & 95.14 & $4,958.7$ & $5,707.95$ \\
\hline July & 214.12 & 78.14 & 110.66 & $4,741.42$ & $5,479.92$ \\
\hline August & 147.82 & 71.96 & 76.02 & $4,402.44$ & $5,001.46$ \\
\hline September & 211.24 & 85.36 & 73.40 & $4,742.12$ & $5,416.40$ \\
\hline October & 206.15 & 97.64 & 109.18 & $4,988.96$ & $5,770.29$ \\
\hline November & 210.72 & 96.06 & 105.90 & $4,804.3$ & $5,551.04$ \\
\hline December & 213.94 & 92.8 & 128.22 & $5,046.88$ & $5,775.04$ \\
\hline Total & $2,553.40$ & $1,100.12$ & $1,244.66$ & $58,512.44$ & $67,307.42$ \\
\hline $\operatorname{AGR}\left(\operatorname{kg~inh}^{-1} y^{-1}\right)$ & 14.17 & 6.10 & 6.91 & 324.70 & 373.51 \\
\hline DGR $\left(\mathrm{kg} \mathrm{inh}^{-1} \mathbf{d}^{-1}\right)$ & 0.04 & 0.02 & 0.02 & 0.89 & 1.02 \\
\hline
\end{tabular}




\subsection{Street network design}

One of the steps needed to draw the MSW map is to insert the town street network. In the case-study, the basic street network was downloaded from the website of the IGN, which belongs to the Spanish Ministry of Public Works and Transport. The street network was loaded into ArcGIS but the network needed to be updated, as the city has changed in the last few years. In fact, new streets that were not in the original network and new roundabouts were digitised. Afterwards, all the information about the streets such as street length, street width, street traffic direction and forbidden turns were introduced as needed input. The final street network of the study area is shown in Figure 3. To verify that the street network was correctly connected, first several routes were calculated.

- Linear density of population (ldp): There is no a database available that contains the number of inhabitants per household, which would provide detailed data. This would be the most accurate method to obtain the linear density of the population. The primary data in the study area was Castellón Council's register of inhabitants, which divides the town into sections. To obtain the linear density of each section, firstly, the pavement length of each section (pav length sect) must be measured in accordance with the following equation (3):

$$
\text { pav length sect }(m)=2 \times l_{\text {intstreet }}+l_{\text {perstreet }}
$$

Where $l_{\text {intstreet }}$ is the length of interior streets in each section and $l_{\text {perstreet }}$ is the length of the perimeter streets in each section.

Secondly, the number of inhabitants per section must be divided by the pavement length in each section to obtain the linear density of the population $(l d p=$ no. of inhabitants per metre of pavement). Figure 3 shows the results for the study area.

Figure 3. Linear densities of population within land-registry sections.

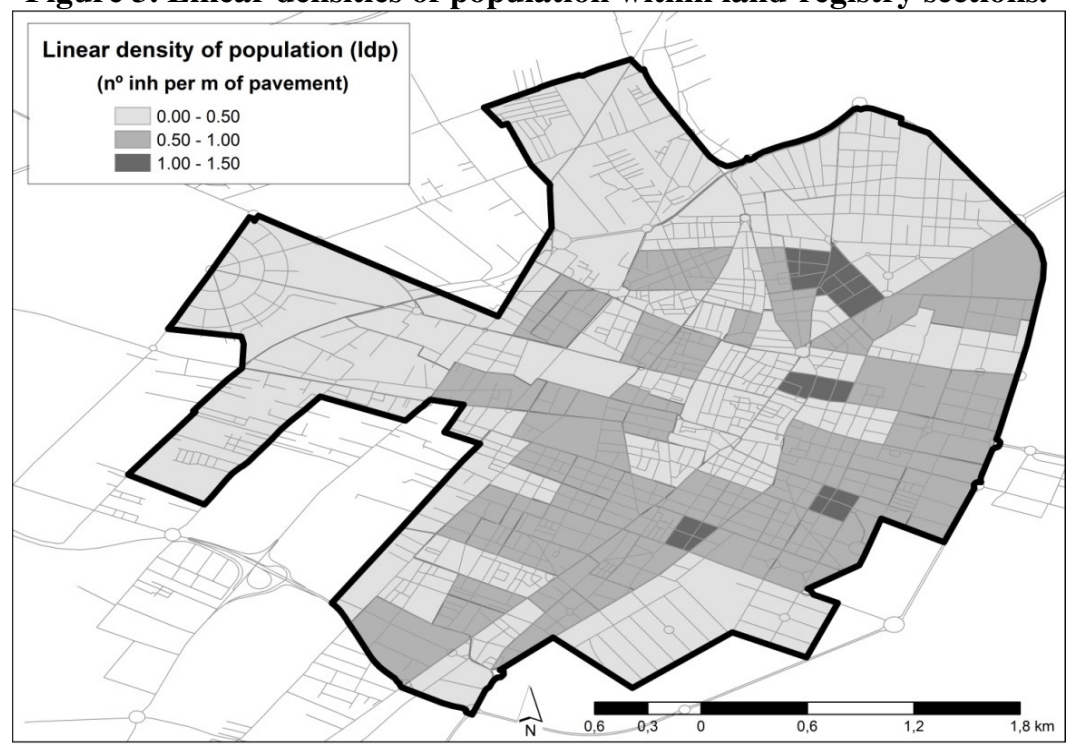

- Shop distribution: Council data about economic activity make it possible to map the spatial distribution of the points where there is commercial activity in this town. Nevertheless, there is no complete information about the type of commercial activity that is carried out in each business. 


\subsection{Design of the MSW map of Castellón}

The MSW map will be drawn following the proposed indirect way, as was pointed out in the problem definition section (section 3.1.). The factors that affect MSW generation, presented in Table 1, have been analysed. Afterwards, thematic maps of the factors which show differences amongst districts in the study area must also be represented. Therefore, the thematic maps of the economic activity and the economic level of the population must be drawn.

- Map of economic activity: In this town, according to Council economic activity data, there are many different economic activities that would complicate a spatial analysis, and the subsequent homogeneous areas would be too small to analyse them. Therefore, the economic activities have been classified into four main groups (residential, commercial, residential-commercial and industrial). The residential group involves activities such as education, sports facilities, religious buildings, and households. The commercial group involves activities like shops, hotels, offices, public authorities and entertainment. The commercial-residential group includes housing, commercial premises and offices, and finally the industrial group comprises all kinds of industries. Since industrial waste is not included in MSW, this last category has not been taken into account to draw the MSW map; the categories considered the three main uses are the commercial, the residential and the commercial-residential ones, they are shown in figure 4. Commercial-residential activity is concentrated in the town centre, and the zones which are mainly commercial are scarcely present in the study area.

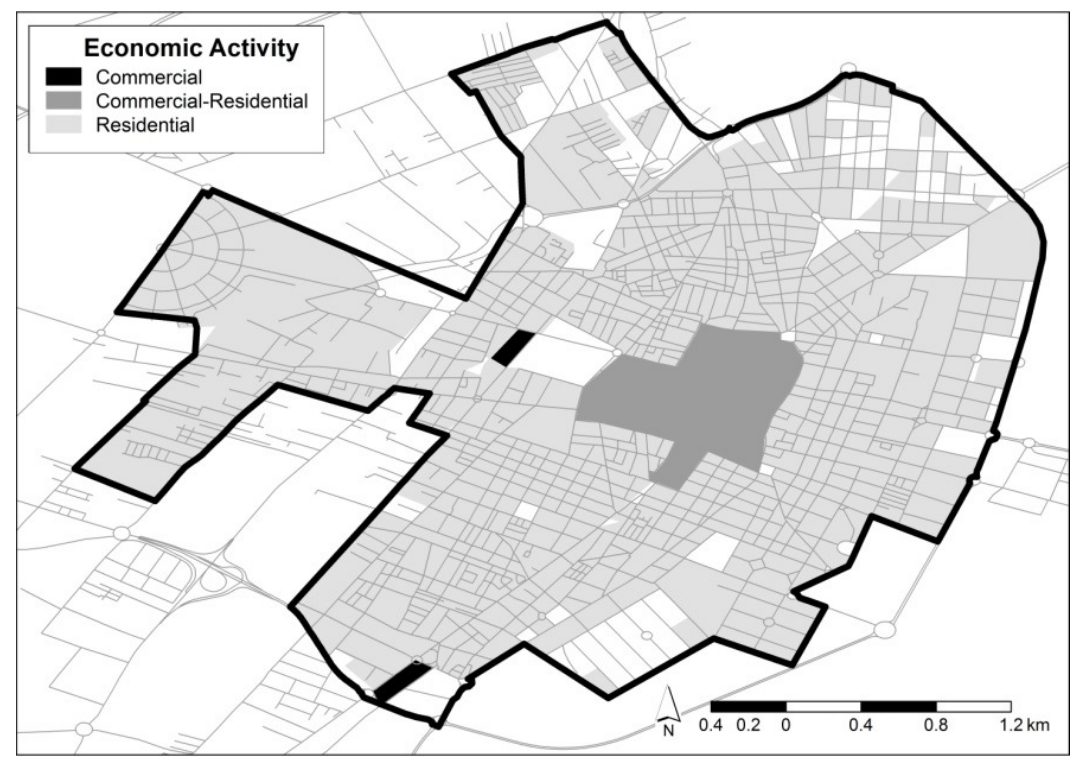

Figure 4. Spatial distribution of three main economic activities: Residential, Commercial and Commercial-Residential.

- Map of the Economic level of the population: According to Council data, the area under study is divided into 46 land value zones, whose land economic values are between 171 and $946 € / \mathrm{m}^{2}$. In this methodology four levels have been used to characterise the economic level of the population. These levels were defined as: low $\left(150-250 € \mathrm{~m}^{-2}\right)$, medium (250-500€ $\left.\mathrm{m}^{-2}\right)$, medium-high $\left(500-700 € \mathrm{~m}^{-2}\right)$ and high $(700-$ $950 € \mathrm{~m}^{-2}$ ). The resulting map shown in Figure 5 reflects a concentrated area of high values in the town centre, and the lowest values are found in the western districts of the town. 


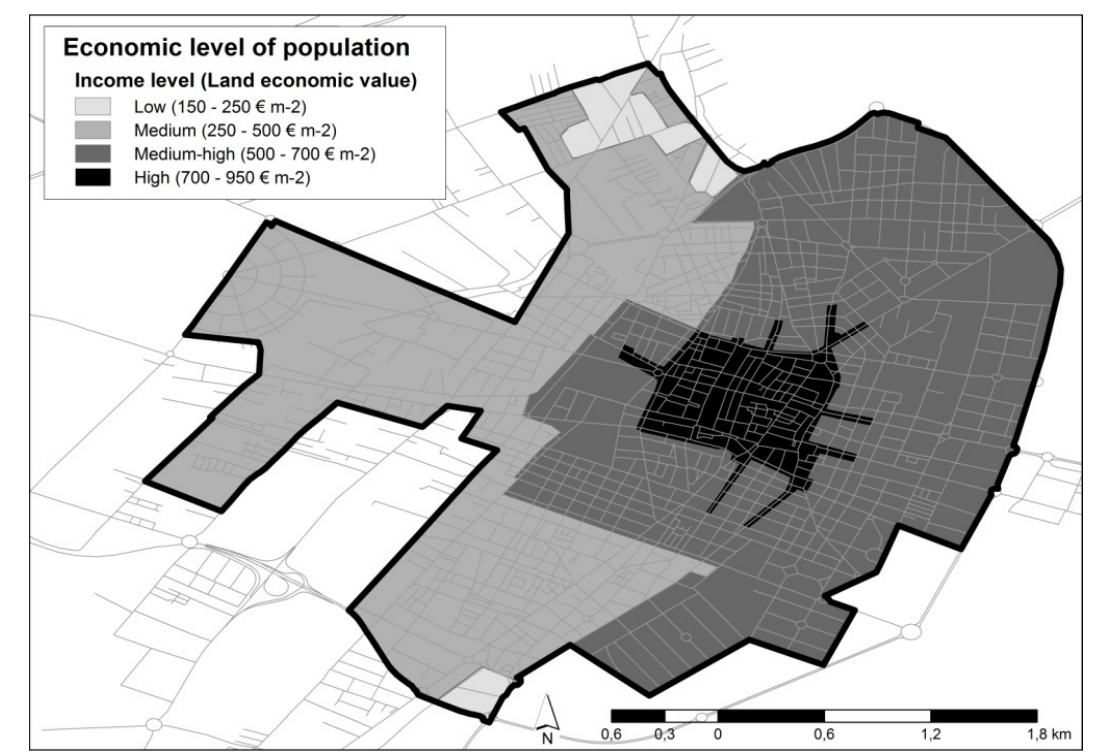

Figure 5. Spatial distribution of the Economic level of the population, taking into account land economic zones $\left(€ \mathrm{~m}^{-2}\right)$.

At this stage, the homogeneous subareas were obtained by intersecting the economic activity map and the economic level of the population map, using GIS geoprocessing tools. If three types of economic activity (commercial, commercial-residential and residential) and four economic levels are taken into account, the results show twelve types of homogeneous subareas, which are listed in Table 3. However, only nine types of homogeneous subareas appear in the study area, these areas are shown in Figure 6. Finally, MSW generation was obtained for only six types of subarea, from 7 to 12 , since waste from commercial areas was not calculated.

Table 3. Types of homogeneous sectors depending on the economic activity and value of the land in

\begin{tabular}{lllll}
\hline Subarea Type & Economic activity & $\begin{array}{l}\text { Castellón. } \\
\text { Income value (Land } \\
\text { economic value) }\end{array}$ & Present & Calculated \\
\hline $\mathbf{1}$ & Commercial & $1\left(150-250 € \mathrm{~m}^{-2}\right)$ & Yes & No \\
$\mathbf{2}$ & Commercial & $2\left(250-500 € \mathrm{~m}^{-2}\right)$ & Yes & No \\
$\mathbf{3}$ & Commercial & $3\left(500-700 € \mathrm{~m}^{-2}\right)$ & Yes & No \\
$\mathbf{4}$ & Commercial & $4\left(700-950 € \mathrm{~m}^{-2}\right)$ & No & No \\
$\mathbf{5}$ & Commercial-Residential & 1 & No & No \\
$\mathbf{6}$ & Commercial-Residential & 2 & No & No \\
$\mathbf{7}$ & Commercial-Residential & 3 & Yes & Yes \\
$\mathbf{8}$ & Commercial-Residential & 4 & Yes & Yes \\
$\mathbf{9}$ & Residential & 1 & Yes & Yes \\
$\mathbf{1 0}$ & Residential & 2 & Yes & Yes \\
$\mathbf{1 1}$ & Residential & 3 & Yes & Yes \\
$\mathbf{1 2}$ & Residential & 4 & Yes & Yes \\
\hline
\end{tabular}




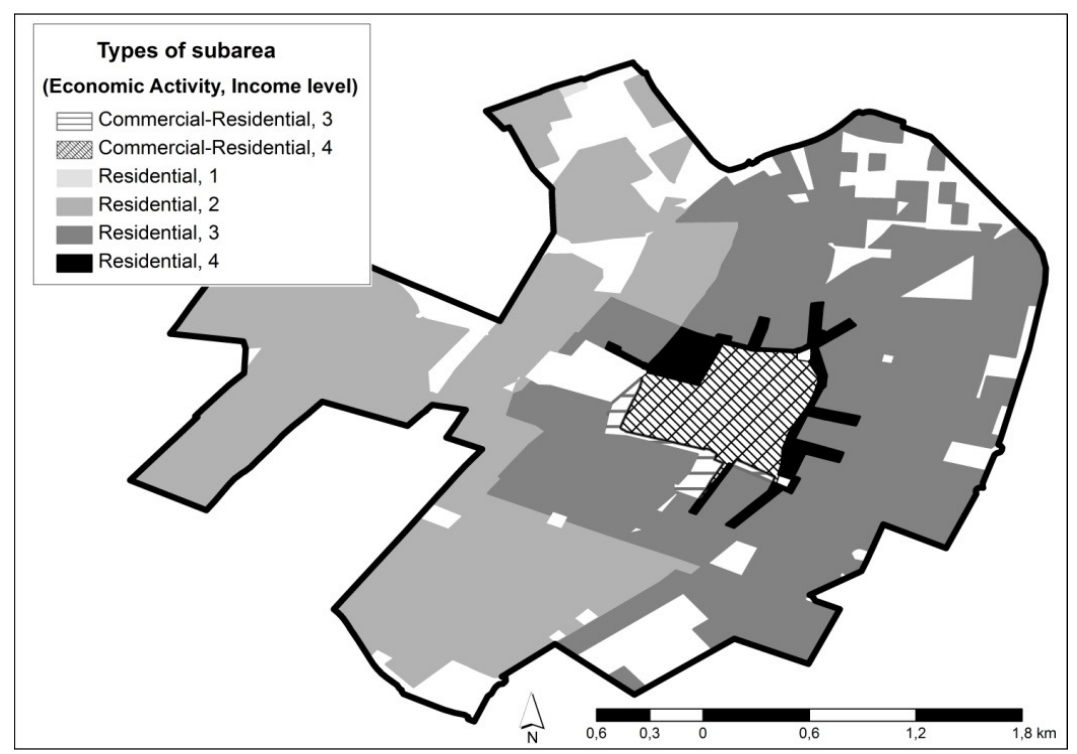

Figure 6. Study area divided into homogeneous subareas.

Each subarea needs additional information about MSW composition and generation. In this case, there is information available about MSW generation for the entire town, whereas there is no detailed information about MSW generation or composition for these six types of subareas. Therefore, these general data about the study area and some additional bibliographic information were used to establish the coefficients that were needed.

\subsubsection{Calculating the $D G R m_{i l}$ of each subarea}

The $D G R m_{i l}$ of each subarea is calculated using equation 1 . In this equation, first the coefficients $\left(\mathrm{Cmv}_{i}, \mathrm{C}_{I l}\right.$ and $\left.\mathrm{Cea}_{l}\right)$ must be defined. These coefficients could be obtained from bibliographical sources or by taking into account the data that were compiled. In this study, $C_{I l}$ was obtained from the literature, whereas $C m v_{i}$ and $C e a_{l}$ were calculated from data about the study area.

- The Monthly Variation Coefficients $\left(\mathrm{Cmv}_{i}\right)$. These coefficients were calculated from monthly data about MSW in 2012 as shown in Table 4. The lowest variation coefficient is found in August because Castellón is not a touristic town and the population decreases during the summer, especially in August. In fact, similar results were found in Castellón between 1986 and 1997 and in other non-touristic towns (Gallardo, 2000).

Table 4. Monthly variation coefficient $\left(C m v_{i}\right)$.

\begin{tabular}{lccccc}
\hline & $\begin{array}{c}\text { MSW Generation } \\
\left(\mathbf{t ~ m o n t h}^{\mathbf{1}} \mathbf{)}\right.\end{array}$ & $\mathbf{C m v}_{\mathbf{i}}$ & $\begin{array}{c}\text { Castellón } \\
\mathbf{( 8 6 - 9 7 )}\end{array}$ & $\begin{array}{c}\text { Cities with } \\
\text { seasonal tourism }^{\mathbf{1}}\end{array}$ & $\begin{array}{c}\text { Cities without } \\
\text { seasonal tourism }^{\mathbf{1}}\end{array}$ \\
\hline January & $5,805.20$ & 1.03 & 1.03 & 0.93 & 1.05 \\
February & $5,196.43$ & 0.93 & 0.96 & 0.82 & 0.93 \\
March & $6,094.73$ & 1.09 & 1.06 & 1.00 & 1.02 \\
April & $5,551.59$ & 0.99 & 1.01 & 0.92 & 1.00 \\
May & $5,957.37$ & 1.06 & 1.08 & 0.97 & 1.06 \\
June & $5,707.95$ & 1.02 & 1.01 & 1.05 & 1.03 \\
July & $5,479.92$ & 0.98 & 0.96 & 1.29 & 0.99 \\
August & $5,001.46$ & 0.89 & 0.87 & 1.38 & 0.85 \\
September & $5,416.40$ & 0.97 & 0.96 & 1.01 & 0.99 \\
October & $5,770.29$ & 1.03 & 1.04 & 0.89 & 1.05 \\
November & $5,551.04$ & 0.99 & 0.98 & 0.85 & 0.99 \\
December & $5,775.04$ & 1.03 & 1.05 & 0.89 & 1.06 \\
Annual Average & $67,307.42$ & & & &
\end{tabular}


- The Income Coefficients $\left(C_{I} l\right)$ : In the study area, the land economic value is used to calculate the income coefficient. Thus, four ranges of land economic values were related to income levels, which were in turn later linked to the income coefficient. These coefficients were determined by Gallardo (2000) and the equivalent relation between those data is presented in Table 5.

Table 5. Income Coefficients $\left(\mathrm{C}_{\mathrm{II}}\right)$.

\begin{tabular}{lll}
\hline Income levels & $\begin{array}{l}\text { Ranges of land } \\
\text { Economic Value }\left(\mathbf{E ~}^{\mathbf{- 2}}\right)\end{array}$ & $\begin{array}{l}\text { Income } \\
\text { Coefficient }^{\mathbf{1}}\end{array}$ \\
\hline 1. Low income & $150-250$ & 0.75 \\
2. Medium income & $250-500$ & 0.85 \\
3. Medium-higher income & $500-700$ & 1 \\
4. Higher income & $700-950$ & 1.1 \\
\hline \multicolumn{2}{l}{} \\
& ${ }^{1}$ Source: Gallardo (2000)
\end{tabular}

- The Economic activity coefficients (Cea l): As there are no bibliographical data available about similar cities, the $\mathrm{Ce}_{l}$ is calculated taking into account the data supplied by Castellón Council. In this town, the paper-cardboard fraction from commercial activities located in the town centre is collected door to door. The amount of papercardboard collected can be considered to be closely related to the amount generated. Therefore, the economic activity coefficient is calculated from the Annual Rates of MSW for zones with commercial-residential and residential economic activity using equation (4) and the coefficients are 0.99 for residential area and 1.05 for residentialcommercial area.

$\mathrm{Cea}_{l}=$ Annual Rate $_{1} /$ Annual Rate of the town

where 1 is the subarea with economic activity: Residential or Residential-Commercial.

The $\mathrm{DGRm}_{\mathrm{il}}$ for each subarea type has been calculated from equation (1) and the final results are presented in Table 6. The highest DGRm value is $1.26 \mathrm{~kg} \mathrm{inh}^{-1} \mathrm{~d}^{-1}$ (subarea type 8 in March), whereas the smallest DGRm value is $0.67 \mathrm{~kg} \mathrm{inh}^{-1} \mathrm{~d}^{-1}$ (subarea type 9 in August). As a result, the highest value is almost twice the lowest one. From the monthly perspective, the August coefficient is the smallest one, due to the fact that the smallest rates were found in August in all the subarea types.

Table 6. DGRm of each month for each subarea type $\left(\mathrm{kg} \mathrm{inh}^{-1} \mathrm{~d}^{-1}\right)$.

\begin{tabular}{lcccccccccccc}
\hline \multicolumn{10}{c}{} & \multicolumn{10}{c}{ DGRm $_{\mathrm{i}, \mathrm{I}}$} \\
$\begin{array}{l}\text { Subarea } \\
\text { type }\end{array}$ & Jan & Feb & Mar & Apr & May & Jun & Jul & Aug & Sep & Oct & Nov & Dec \\
\hline $\mathbf{7}$ & & & & & & & & & & & & \\
$\mathbf{8}$ & 1.09 & 1.08 & 1.15 & 1.08 & 1.12 & 1.11 & 1.03 & 0.94 & 1.05 & 1.08 & 1.08 & 1.09 \\
$\mathbf{9}$ & 0.78 & 1.19 & 1.26 & 1.19 & 1.23 & 1.22 & 1.13 & 1.03 & 1.16 & 1.19 & 1.19 & 1.19 \\
$\mathbf{1 0}$ & 0.77 & 0.82 & 0.77 & 0.80 & 0.79 & 0.73 & 0.67 & 0.75 & 0.77 & 0.77 & 0.77 \\
$\mathbf{1 1}$ & 0.88 & 0.87 & 0.92 & 0.87 & 0.90 & 0.89 & 0.83 & 0.76 & 0.85 & 0.88 & 0.87 & 0.88 \\
$\mathbf{1 2}$ & 1.04 & 1.03 & 1.09 & 1.02 & 1.06 & 1.05 & 0.98 & 0.89 & 1.00 & 1.03 & 1.02 & 1.03 \\
\hline & 1.14 & 1.13 & 1.20 & 1.13 & 1.17 & 1.16 & 1.08 & 0.98 & 1.10 & 1.13 & 1.13 & 1.13 \\
\hline
\end{tabular}

\subsubsection{Calculating Generation Rate per pavement $(\mathrm{kg} / \mathrm{m})$ in each subarea.}

There are six types of subareas in the study area, as Figure 6 shows. Nevertheless, in each subarea there are several population sections with differences between their $l d p$ as shown in Figure 3. The MSW Generation Rate per metre of pavement is obtained considering the $D G R m_{i}$ of each subarea and the ldp of every section located in the subarea. Consequently, there are important differences in MSW generation within one type of subarea due to higher density population areas would generate more MSW than lower density population areas in the same subarea type. For example, a $D G R m$ map per 
metre of pavement for January is shown in Figure 7. This map is the result of intersecting the subareas map (Figure 6) with the inhabitant density map (Figure 3), which draws out homogeneous areas with a similar generation rate per metre of pavement. Furthermore, this map shows that there are great differences around the town. However, the greatest influence of the population is also shown, since the highest $D G R m$ per metre of pavement are found in the areas with the highest population densities.

Figure 7. DGRm per $\mathrm{m}$ of pavement in January for each subarea type $\left(\mathrm{kg} \mathrm{m}^{-1} \mathrm{~d}^{-1}\right)$.

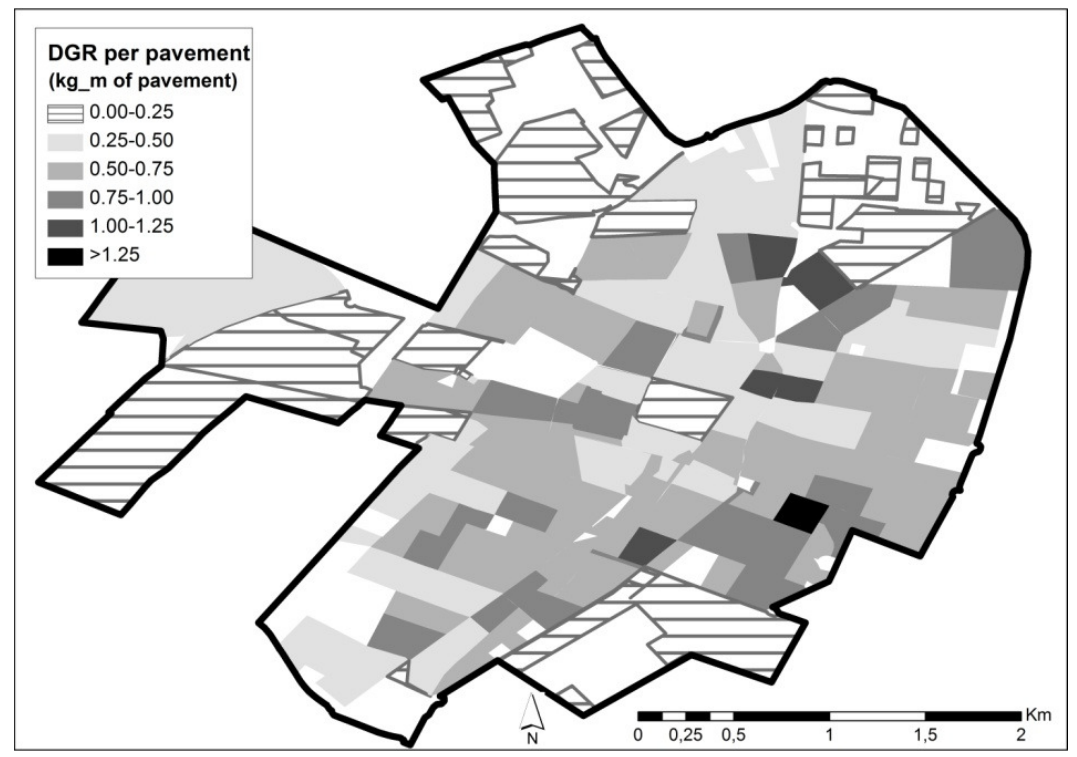

The results of every subarea type are summarized in the table 7 , in order to know the average behaviour of each type of subarea. In this table the average values and maximum and minimum values of MSW generation rate per metre of pavement for every month for the six subareas type are shown. The values obtained in the study area vary from $0.05 \mathrm{~kg} \mathrm{~m}^{-1} \mathrm{~d}^{-1}$, which belong to a population section of the subarea type 11 during the month of August, to $1.33 \mathrm{~kg} \mathrm{~m}^{-1} \mathrm{~d}^{-1}$ which belongs to a population section of the subarea type 11 during the month of March. In fact, the minimum values appear in August for every subarea type. On the other hand, the maximum values appear in March for some subarea types whereas in others subareas type appear in May. This information would be very useful to design different collection routes over the year as the MSW generation rate per meter also varies

Table 7. DGRm per metre of pavement for each month for each subarea type $\left(\mathrm{kg} \mathrm{m}^{-1} \mathrm{~d}^{-1}\right)$. DGR per $\mathrm{m}$ of pavement $\left(\mathrm{kg} \mathrm{m}^{-1} \mathrm{~d}^{-1}\right)$

\begin{tabular}{cccccccccccccc}
\hline $\begin{array}{l}\text { Subarea } \\
\text { ype }\end{array}$ & & Jan & Feb & Mar & Apr & May & Jun & Jul & Aug & Sep & Oct & Nov & Dec \\
\hline $\mathbf{7}$ & Average & 0.58 & 0.58 & 0.61 & 0.57 & 0.60 & 0.59 & 0.55 & 0.50 & 0.56 & 0.58 & 0.57 & 0.58 \\
& St. Dev. & 0.17 & 0.17 & 0.18 & 0.17 & 0.17 & 0.17 & 0.16 & 0.14 & 0.16 & 0.17 & 0.17 & 0.17 \\
& Min & 0.33 & 0.32 & 0.34 & 0.32 & 0.34 & 0.33 & 0.31 & 0.28 & 0.32 & 0.33 & 0.32 & 0.33 \\
& Max & 0.85 & 0.84 & 0.89 & 0.84 & 0.87 & 0.86 & 0.80 & 0.73 & 0.82 & 0.85 & 0.84 & 0.85 \\
$\mathbf{8}$ & Average & 0.60 & 0.59 & 0.63 & 0.59 & 0.61 & 0.61 & 0.56 & 0.52 & 0.58 & 0.59 & 0.59 & 0.60 \\
& St. Dev & 0.25 & 0.25 & 0.26 & 0.25 & 0.25 & 0.25 & 0.23 & 0.21 & 0.24 & 0.25 & 0.25 & 0.25 \\
& Min & 0.22 & 0.21 & 0.23 & 0.21 & 0.22 & 0.22 & 0.20 & 0.19 & 0.21 & 0.21 & 0.21 & 0.21 \\
& Max & 1.24 & 1.23 & 1.30 & 1.22 & 1.27 & 1.26 & 1.17 & 1.07 & 1.19 & 1.23 & 1.22 & 1.23
\end{tabular}




\begin{tabular}{cccccccccccccc}
9 & Average & 0.35 & 0.34 & 0.36 & 0.34 & 0.36 & 0.35 & 0.33 & 0.30 & 0.33 & 0.35 & 0.34 & 0.35 \\
& St. Dev. & 0.20 & 0.19 & 0.21 & 0.19 & 0.20 & 0.20 & 0.18 & 0.17 & 0.19 & 0.19 & 0.19 & 0.19 \\
& Min & 0.12 & 0.12 & 0.12 & 0.12 & 0.12 & 0.12 & 0.11 & 0.10 & 0.11 & 0.12 & 0.12 & 0.12 \\
& Max & 0.62 & 0.62 & 0.65 & 0.61 & 0.64 & 0.63 & 0.59 & 0.54 & 0.60 & 0.62 & 0.61 & 0.62 \\
\multirow{2}{*}{10} & Average & 0.45 & 0.45 & 0.47 & 0.45 & 0.46 & 0.46 & 0.43 & 0.39 & 0.44 & 0.45 & 0.45 & 0.45 \\
& St. Dev. & 0.21 & 0.21 & 0.22 & 0.21 & 0.22 & 0.22 & 0.20 & 0.18 & 0.21 & 0.21 & 0.21 & 0.21 \\
& Min & 0.11 & 0.11 & 0.12 & 0.11 & 0.12 & 0.12 & 0.11 & 0.10 & 0.11 & 0.11 & 0.11 & 0.11 \\
\multirow{2}{*}{11} & Max & 0.88 & 0.87 & 0.92 & 0.87 & 0.90 & 0.89 & 0.83 & 0.76 & 0.85 & 0.88 & 0.87 & 0.88 \\
& Average & 0.63 & 0.62 & 0.66 & 0.62 & 0.64 & 0.64 & 0.59 & 0.54 & 0.61 & 0.62 & 0.62 & 0.62 \\
& St. Dev. & 0.25 & 0.24 & 0.26 & 0.24 & 0.25 & 0.25 & 0.23 & 0.21 & 0.24 & 0.25 & 0.24 & 0.25 \\
& Min & 0.06 & 0.06 & 0.07 & 0.06 & 0.06 & 0.06 & 0.06 & 0.05 & 0.06 & 0.06 & 0.06 & 0.06 \\
& Max & 1.26 & 1.25 & 1.33 & 1.25 & 1.30 & 1.28 & 1.19 & 1.09 & 1.22 & 1.26 & 1.25 & 1.26 \\
& Average & 0.64 & 0.63 & 0.67 & 0.63 & 0.65 & 0.65 & 0.60 & 0.55 & 0.61 & 0.63 & 0.63 & 0.63 \\
& St. Dev. & 0.20 & 0.20 & 0.21 & 0.20 & 0.21 & 0.20 & 0.19 & 0.17 & 0.19 & 0.20 & 0.20 & 0.20 \\
& Min & 0.39 & 0.38 & 0.41 & 0.38 & 0.40 & 0.39 & 0.37 & 0.33 & 0.37 & 0.39 & 0.38 & 0.39 \\
& Max & 1.17 & 1.16 & 1.23 & 1.16 & 1.20 & 1.19 & 1.11 & 1.01 & 1.13 & 1.17 & 1.16 & 1.17 \\
\hline
\end{tabular}

\subsubsection{Composition calculation in each subarea.}

There is no information available about the influence of the socio-economic factor on MSW generation that can be used to calculate the composition coefficients or about other similar areas.

Moreover, there is only general information about MSW composition in the study area. Consequently, sampling work must be carried out in each type of subarea but this involves making a great economic effort, as well as being very time-consuming.

\section{Conclusions}

An efficient MSW management plan is needed in every town to assure a healthy living standard, to protect the environment and the natural resources. To manage MSW adequately, a great amount of information about waste composition and generation is needed. Several socio-economic factors such as population density, seasonal variation of population, the economic activity of the population, the type of commercial areas and the economic level of the population must be taken into account to design a good MSW management plan. This information may vary spatially around the town and temporarily. As the amount of information needed is considerable, a methodology that describes and organizes all these data combined with Geographic Information Systems to obtain graphical results have been presented in this paper.

The proposed methodology allows the final user to represent the waste generation cartography of a town, taking into account socio-economic variables such as economic activity, income and population density. This methodology is adaptable to the town's necessities as the first step consists in defining the town typology, the inhabitants' distribution as well as the type of waste to be characterised.

As the available data are not always as detailed as needed, the methodology offers two possible ways to achieve a good MSW generation map. It proposes on the one hand, a direct way if the information is complete and detailed and an on the other hand, an indirect way if there is a lack of information which in some cases may be quite common. In this second case, the methodology guides the user to calculate the daily 
generation rate per month and town subarea and the waste composition per town subarea from theoretical coefficients. Therefore, in any case the final user will be able to define the town MSW characteristics and to build the corresponding thematic map that will improve MSW management.

Although the quality of the information available will have an influence on the final map, it should be noted that the waste generation data can be obtained per metre of pavement.

The methodology has been verified applying it to a real case. The case study presented corresponds to Castellón, a Spanish city. Following the methodology step by step, maps such as the spatial distribution of the main economic activities of the town, the spatial distribution of the economic level of the population, the map of the town sectors with the same land use and land value have been drawn to finally obtain the map of the Daily Generation Rate per metre of pavement in a specific month.

In the study case, the methodology has allowed to conclude that the DGR varies according to the month of the year. It has also shown how DGR varies depending on the town subarea type. This information is highly important in order to design different collection routes over the year as the MSW generation rate per meter also varies

This methodology allows the final user to represent the information about any of the waste fraction generated in the town as the organic waste, the paper and cardboard, the light packaging or the glass fraction. Therefore, the user will be able to know the spatial distribution of the MSW fraction selected, as well as its composition and temporal variability with a high level of detail. This will be a required work to do before taking into account other waste management tasks such as the bins allocation or the optimization of the waste collection routes.

As a result, this methodology is considered a very useful tool for the technical staff, local authorities or private companies dealing with the MSW management planning to improve it and consequently to achieve better economical and environmental benefits.

\section{References}

Anghinolfi, D., Paolucci, M., Robba, M., Taramasso, A.C., 2013. A dynamic optimization model for solid waste recycling. Waste Manage 33, 287-296.

Ariza, E., Jiménez, J. A., Sarda, R., 2008. Seasonal evolution of beach waste and litter during the bathing season on the Catalan coast. Waste Manage 28, 2604-2613.

Bandara, N. J., Hettiaratchi, J. P., Wirasinghe, S. C., Pilapiiya, S., 2007. Relation of waste generation and composition to socio-economic factors: a case study. Environ. Monit. and Assess. 135(1-3), 31-39.

Beigl, S., Lebersorger, S., Salhofer S., 2008. Modelling municipal solid waste generation: A review. Waste Manage 28, 200-214.

Beigl, P., Wassermann, G., Schneider, F., Salhofer, S., 2004. Forecasting municipal solid waste generation in major European cities, in: Pahl-Wostl, C., Schmidt, S., Jakeman, T. (Eds.), iEMSs 2004 Intern. Congress: "Complexity and Integrated Resources Management”. Osnabrueck, Germany.

Boldrin, A., Christensen, T.H., 2010. Seasonal generation and composition of garden waste in Aarhus (Denmark). Waste Manage 30, 551-557.

Bovea, M.D., Ibáñez-Forés, V., Gallardo, A., Colomer-Mendoza, F.J., 2010. Environmental assessment of alternative municipal solid waste management strategies. A Spanish case study. Waste Manage 30, 2383-2395. 
Castagna, A., Casagranda, M., Zeni, A., Girelli, E., Rada, E.C., Ragazzi, M., Apostol, T., 2013. 3R'S from citizens point of view and their proposal from a case-study. UPB Sci Bul, series D, 75(4), 253-264.

Castellón Town Council. 2010. Register of inhabitants.

Chalkias, C., Lasaridi, K., 2011. Benefits from GIS Based Modelling for Municipal Solid Waste Management, Integr. Waste Manage - Volume I, Mr. Sunil Kumar (Ed.), ISBN: 978-953-307-469-6, InTech, Available from: http://www.intechopen.com/books/integrated-waste-management-volumei/benefitsfrom-gis-based-modelling-for-municipal-solid-waste-management

Cherian, J., Jacob, J., 2012. Management Models of Municipal Solid Waste: A Review Focusing on Socio Economic Factors. Int. J. of Economics and Finance 4-10, 131-139.

Daskalopoulos, E., Badr, O., Probert, S.D., 1998. Municipal solid waste: a prediction methodology for the generation rate and composition in the European Union countries and the United States of America. Resour., Conservation and Recycl. 24, 155-166.

Dahlén, L., Åberg, H., Lagerkvist, A., Berg, P:E.O., 2009. Inconsistent pathways of household waste. Waste Manage 29, 1798-1806.

Economopoulos, A.P., 2012. Planning Tools and Procedures for Rational Municipal Solid Wastes Management. Green Energy and Technol., 55, 27-57.

Emery, A.D., Griffiths, A.J., Williams, K.P., 2003. An in depth study of the effects of socio-economic conditions on household waste recycling practices. Waste Manage \& Res. 21, 180-190.

Ericsson, E., Larsson, H., Brundell-Freij, K., 2006.Optimizing route choice for lowest fuel consumption-Potential effects of a new driver support tool. Transp. Res. Part C 14, 369-383.

EUROSTAT, 2013. Municipal waste generation and treatment, by type of treatment method (kg per capita)

http://epp.eurostat.ec.europa.eu/tgm/table.do?tab=table\&init=1\&plugin=1\&language=e $\underline{\mathrm{n} \& \mathrm{pcode}=\mathrm{tsdpc} 240}(13 / 01 / 2014)$

Gallardo, A. 2000. ThesisPh. Metodología para el diseño de redes de recogida selectiva de RSU utilizando sistema de Información Geográfica. Creación de una Base de datos aplicable a España. Universidad Politécnica de Valencia.

Gallardo, A., Bovea, M.D., Colomer, F., Prades, M., Carlos, M., 2010. Comparison of different collection systems for sorted household waste in Spain. Waste Manage 30, 2430-2439.

Gallardo, A., Gómez, A., Bovea, M.D., Colomer, F., Carlos, M., 2011. Determinación de la influencia del factor - nivel de rentall en la eficiencia de la recogida selectiva de residuos urbanos. Caso de estudio Castellón de la Plana (España), in: Hacia la sustentabilidad: Los residuos sólidos como fuente de energía y materia prima, pp. 70-75 ISBN 978-607-607-015-4

Gallardo Izquierdo, A., Bernad Beltrán, D., 2011. 19. Aplicación de los Sistemas de Información Geográfica (SIG) a la Gestión de Residuos: Diseño de una herramienta para la recogida selectiva, in: Marquez Benavidez, L. (Ed), Residuos sólidos: un enfoque multidisciplinario. Libros en red, pp. 613-639. ISBN: 978-1-59754-787-1.

Gómez, G., Meneses, M. Ballinas, L., Castells, F., 2009. Seasonal characterization of municipal solid waste (MSW) in the city of Chihuahua, Mexico. Waste Manage 29, 2018-2024.

Ibáñez, M.V., Prades, M., Simó, A., 2011. Modelling municipal waste separation rates using generalized linear models and beta regression Resour., Conservation and Recycl. 55, 1129 - 1138 . 
IGN (2012) CartoCiudad en centro de descargas. Centro Nacional de Información Geográfica.

http://centrodedescargas.cnig.es/CentroDescargas/buscadorCatalogo.do?codFamilia=02 $122(3 / 02 / 2014)$

INE, 2012. Cifras oficiales de población resultantes de la revisión del Padrón municipal a 1 de enero de 2012.

http://www.ine.es/jaxi/menu.do?type $=$ pcaxis \&path $=\% 2 \mathrm{Ft} 20 \% 2 \mathrm{Fe} 260 \% 2 \mathrm{Fa} 2012 \% 2 \mathrm{~F} \& \mathrm{f}$ ile $=$ pcaxis $\& N=\& L=0(3 / 02 / 2014)$

Ionescu, G., Rada, E.C., Ragazzi, M., Marculescu, C., Badea, A., Apostol, T., 2013. Integrated municipal solid waste scenario model using advanced pretreatment and waste to energy processes, Energy Convers Manage, 76, 1083-1092.

IVE, 2012. Ficha municipal de Castellón de la Plana. Actualización 2012. Institut Valencià d'Estadística.

Karadimas, N., Loumos, V.G., 2008. GIS-based modelling for the estimation of municipal solid waste generation and collection. Waste Manage \& Res. 26, 337-346.

Register of Inhabitants (2010). Dades estadístiques de població de la ciutat de Castelló de la Plana, resultant del tancament numèric realitzat per l'Ajuntament a data d'1 de gener de 2010.

https://www.castello.es/web30/pages/generico_web10.php?cod1 $=453 \& \operatorname{cod} 2=932$ $(3 / 02 / 2014)$

Keser, S., Duzgun, S., Aksoy, A., 2012. Application of spatial and non-spatial data analysis in determination of the factors that impact municipal solid waste generation rates in Turkey. Waste Manage 32, 359-371.

Mateu-Sbert, J., Ricci-Cabello, I., Villalonga-Olives, E., Cabeza-Irigoyen, E., 2013. The impact of tourism on municipal solid waste generation: The case of Menorca Island (Spain). Waste Management 33, 2589-2593.

Mazzanti, M., Montini, A., Zoboli, R., 2008.Municipal Waste Generation and Socioeconomic Drivers Evidence.From Comparing Northern and Southern Italy. The J. of Environ. \& Dev. 17-1, 51-68.

Mendes, P., Carina Santos, A., Nunes, L.M., Ribau Teixeira, M., 2013. Evaluating municipal solid waste management performance in regions with strong seasonal variability. Ecol. Indic. 30, 170-177.

Pitchel, J. 2005. Waste Management Practices: Municipal, Hazardous, and Industrial. Ed. Taylor \& Francis Group. Boca Ratón. pp. 64-68. ISBN: 0-8493-3525-6.

Rada, E.C., Grigoriu M., Ragazzi, M., Fedrizzi, P. 2010. Web oriented technologies and equipments for MSW collection. Proc. of the Int. Conference on Risk Management, Assess. and Mitig., RIMA '10, 150-153.

Rada, E.C., Ragazzi, M., Fedrizzi, P., 2013. Web-GIS oriented systems viability for municipal solid waste selective collection optimization in developed and transient economies. Waste Manage 33, 785-792.

Ragazzi, M., Rada, E.C., 2008. Effects of recent strategies of selective collection on the design of municipal solid waste treatment plants in Italy. WIT Trans. on Ecol. and the Enviro., 109, 613-620.

Sakai, S., Yoshida, H., Hirai, Y., Asari, M., Takigami, H., Takahashi, S., Tomoda, K., Peeler, M.V., Wejchert, J., Schmid-Unterseh, T., Douvan, R., Hathaway, R., Hylander, L.D., Fischer, C., Oh, G.J., Li, J.H., 2011. International comparative study of 3R and waste management policy developments. J Mate Cycles Waste Manage. 13, 86-102.

Santos, L., Coutinho-Rodrigues, J., John, R., 2008.Implementing a multi-vehicle multiroute spatial decision support system for efficient trash collection in Portugal. Current Transp. Res. Part A 42, 922-934. 
Sokka, L., Antikainen, R., Kauppi. P.E. 2007. Municipal solid waste production and composition in Finland-Changes in the period 1960-2002 and prospects until 2020. Resour., Conserv. and Recycl. 50, 475-488.

Vicente, A.B.; Sanfeliu, T., Jordan, M.M. 2011.Comparison between industrial-urban and rural particle stations in a ceramic cluster (NE, Spain). Water, Air, and Soil Pollut. 215, 83-96.

Vijay, R, Gupta, A., Kalamdhad, A.S, Devotta, S., 2005. Estimation and allocation of solid waste to bin through geographical information systems. Waste Manage \& Res. 23, 479-484.

Troschinetz, A.M., Mihelcic, J.R., 2009. Sustainable recycling of municipal solid waste in developing countries. Waste Manage 29, 915-923.

Zaman, A. U., Lehmann, S., 2011. Urban growth and waste management optimization towards 'zerowaste city'. City, Culture and Soc. 2, 177-187.

Zamorano, M., Molero, E., Grindlay, A., Rodríguez, M.L., Hurtado, A., Calvo, F.J., 2009. A planning scenario for the application of geographical information systems in municipal waste collection: A case of Churriana de la Vega (Granada, Spain). Resour., Conservation and Recycl. 54, 123-133. 